\title{
REDES INTERORGANIZACIONAIS: UM MEIO PARA DISSEMINAÇÃO DE PRÁTICAS E CONHECIMENTOS SOBRE SUSTENTABILIDADE INTERORGANIZATIONAL NETWORKS: MEAN FOR DISSEMINATION OF SUSTAINABILITY PRACTICES AND KNOWLEDGE
}

\author{
Adriana Teixeira Bastos ${ }^{1}$ \\ Fátima Regina Ney Matos ${ }^{2}$
}

\section{RESUMO}

O objetivo deste artigo foi caracterizar a estrutura das redes, identificando os atores relevantes no processo de aprendizagem de conhecimentos e práticas sobre sustentabilidade a partir das relações que ocorreram no ambiente configurado como rede interorganizacional no Arranjo Produtivo Local (APL) da piscicultura do açude Castanhão. A abordagem metodológica adotada foi qualitativa e o objeto da presente pesquisa foram as redes formadas para o processo de aprendizagem de conhecimentos e práticas sobre sustentabilidade. Pode-se concluir que as redes observadas no Castanhão tem contribuído não só para o desenvolvimento do APL, como também na disseminação de conhecimentos e práticas sobre sustentabilidade.

Palavras-Chave: Redes interorganizacionais. Piscicultura. Sustentabilidade. Aprendizagem.

\section{ABSTRACT}

This article aims to characterize the structure of the networks, identifying the relevant actors in the learning process of knowledge and practices about sustainability from the relationships that occurred in the environment configured as interorganizational network in the cluster of the pisciculture of the Castanhão dam. The methodological approach adopted was qualitative and the object of the present research was the networks formed for the learning process of knowledge and practices on sustainability. It is concluded that the networks observed in Castanhão have contributed not only to the development of cluster, but also to dissemination of knowledge and practices on sustainability.

Key-words: Interorganizational networks. Pisciculture Sustainability. Learning.

Manuscript first received/Recebido em 22/10/2018 Manuscript accepted/Aprovado em: 18/12/2019

1 Doutora em Administração de Empresas pela Universidade de Fortaleza e Professora da Universidade Estadual do Ceará. E-mail: adriana.bastos@uece.br

2 Doutora em Administração pela Universidade Federal de Pernambuco e Professora do Instituto Superior Miguel Torga, em Coimbra, Portugal. E-mail: fneymatos@globo.com 


\section{INTRODUÇÃO}

O presente artigo é parte de uma pesquisa maior que tem como objeto de investigação o processo de aprendizagem de conhecimentos e práticas sobre sustentabilidade no Arranjo Produtivo Local (APL) da piscicultura do açude Castanhão.

O que, quem, onde e como são aprendidos os conhecimentos e práticas sobre sustentabilidade são as questões discutidas na consecução da pesquisa completa, mas em virtude da limitação do espaço, optou-se para este artigo discutir apenas a questão do "quem" aprende nas interações das redes existentes no APL da piscicultura do açude Castanhão.

$\mathrm{O}$ contexto que permeia a problemática aqui estudada ressalta o fato de que os conceitos de sustentabilidade e desenvolvimento sustentável (DS), com o final do século XX, tornaram-se não só uma base teórica relevante, mas também importante norma social para o desenvolvimento humano aceita em todo o mundo (ROMEIRO, 2001).

Portanto, a pergunta que orienta o presente trabalho de pesquisa é a seguinte: qual a característica das relações presentes na estrutura das redes e os atores relevantes no processo de aprendizagem de conhecimentos e práticas sobre sustentabilidade na rede formada pelo APL da piscicultura do Castanhão?

Cabe ressaltar que a escolha do APL da piscicultura do Castalhão para o desenvolvimento desta pesquisa repousou na expressividade da atividade para a economia do local e do estado, assim como pela rapidez com que a atividade se desenvolveu, uma vez que as primeiras inciativas só começaram a acontecer no ano de 2003.

Sendo assim, o objetivo que se pretende alcançar é caracterizar a estrutura das redes, identificando os atores relevantes no processo de aprendizagem de conhecimentos e práticas sobre sustentabilidade a partir das relações que ocorreram no ambiente configurado como rede interorganizacional existente no APL da piscicultura do açude Castanhão.

\section{REDES INTERORGANIZACIONAIS NA ABORDAGEM DE REDES SOCIAIS}

A partir da segunda metade do século XX, os estudos sobre redes sociais cresceram substancialmente. Segundo Martes et al., (2006), este fenômeno decorreu da mudança no mundo acadêmico, em que se observou a fuga de explicações individualistas, essencialistas e atomistas, em direção a explicações relacionais, contextuais e sistêmicas. Trata-se de uma mudança que vem ocorrendo em diversos campos do Saber (Estudos Organizacionais, Sociologia, Antropologia, Medicina, Física etc.).

Já Castells (1999) considera que o desenvolvimento do modelo de rede fundou-se desde o início nas mudanças ocorridas nos processos produtivos e na forma em como as organizações passaram a se relacionar, não apenas como clientes e fornecedoras de insumos e produtos, mas numa lógica baseada na troca de informações e na cooperação para o desenvolvimento de projetos em conjunto. Uma nova ordem no mercado internacional foi estabelecida, na qual a prioridade de ação das organizações volta-se para uma economia informacional global, pressupondo maior contato e transferência de informações entre as organizações, bem como na utilização de estruturas flexíveis para acompanhar a dinâmica das instituições, culturas, tecnologias e mercados ${ }^{3}$.

\footnotetext{
3 As redes e aglomerações de empresas, funcionando coordenadamente, têm demonstrado ser um antídoto eficiente, mas não infalível, em relação aos efeitos desintegradores causados pela abertura comercial e pela globalização do capital (Amaral Filho, 2005, p.02).
} 
Em adição, a globalização da Economia, na medida em que conduz ao fechamento de empresas que não suportam a concorrência, possibilita a abertura de um novo ciclo econômico, com foco no desenvolvimento de novos empreendimentos, geração de tecnologia e aumento da circulação de renda, notadamente para as pequenas empresas, que ao iniciarem suas atividades com muitas dificuldades de inserção, passam, muitas vezes, a se utilizar de relações com outras organizações, como meio de se estabelecerem no mercado através de estratégias compartilhadas ${ }^{4}$ (TAVARES; MAIA; SILVA, 2010).

Martes et al., (2006) identificam na evolução histórica da análise de redes, especialmente dentro da tradição sociológica, três bases formadoras: estudos sociométricos, apoiados na psicologia gestáltica; estudos desenvolvidos por antropólogos da Universidade de Manchester e estudos desenvolvidos pelos estruturalistas da Universidade Harvard.

Cabe destacar que a presente pesquisa tem base voltada para os estudos desenvolvidos na Universidade de Manchester. Duas abordagens podem ser creditadas a este grupo: a utilização das redes egocêntricas, isto é, a análise de redes em torno de um indivíduo específico e a análise do conteúdo dos laços da rede por meio de abstrações que descrevem modos particulares de atividade social, tais como parentesco, interação política, amizade e relações de trabalho (MARTES et al., 2006). Sendo assim, a ênfase do presente trabalho será no conteúdo dos laços da rede constituídos com as práticas e conhecimentos que são aprendidos ao longo do desenvolvimento da rede formada pelo APL da piscicultura do Castanhão.

No tocante à nomenclatura utilizada para designar essas formações, cabe lembrar que a rede social é constituída por um conjunto de atores e uma ou mais relações entre estes atores, assim como a rede é flexível na sua aplicabilidade a diferentes tipos de atores e a diferentes tipos de relações. Para as redes sociais, atores podem ser qualquer tipo de unidade social significativa, incluindo indivíduos, entidades coletivas, empresas ${ }^{5}$, organizações e divisões dentro das organizações, bem como agentes não humanos (LATOUR, 1999; LAW, 1992) como repositórios de conhecimento. As relações podem ser de qualquer tipo de interação entre os atores, incluindo relações formais, expressões afetivas (amizade, respeito), interações sociais, fluxos de trabalho, transferências de recursos materiais (dinheiro, bens), publicação e recuperação de conhecimento, fluxos de recursos não materiais (informação, aconselhamento), alianças de negócios etc (CONTRACTOR; WASSERMAN; FAUST, 2006).

Redes interorganizacionais podem ser consideradas como grupos de organizações legalmente separadas, ligadas entre si através de relações de trocas, objetivos comuns e ou obrigações comuns ou de relações sociais sustentadas ao longo do tempo (WILLIAMS, 1998).

Também são conhecidas tipologias cujo foco reside nos diferentes tipos de relações identificadas nas redes. Julien (2000a apud BORGES JÚNIOR, 2004) indica quatro diferentes tipos de redes das quais normalmente o empreendedor faz parte: 1) redes de negócios, constituídas com fins comerciais; 2) redes institucionais, que comportam as relações das pequenas e médias empresas (PMEs) com órgãos governamentais, organizações não-governamentais (ONGs) e instituições acadêmicas; 3) redes pessoais, que são as relações familiares e de amizade do empreendedor; 4) redes informacionais, que compreendem os diferentes contatos pessoais e institucionais com os quais o empreendedor troca informações e conhecimentos. Segundo o autor, as redes informacionais desempenham papel importante na dinâmica de aprendizagem e inovação das PMEs.

4 Klein et al. (2014) consideram que as parcerias assumem a forma de rede na tentativa de diminuir a vulnerabilidade das empresas que reconhecem suas limitações em agir isoladamente e em aumentar seu poder de barganha e firmar posição no mercado em relação a seus concorrentes.

${ }_{5}$ Quando se fala em redes entre empresas ou redes interorganizacionais está se falando de redes sociais. 
Szarka (1990 apud BORGES JÚNIOR, 2004) também apresenta uma tipologia com três tipos de rede: rede de trocas, rede de comunicação e rede social. A rede de trocas é formada pelas empresas e organizações com as quais a PME tem relações comerciais. A rede de comunicações é constituída por organizações ou pessoas com as quais a PME tem relações com o objetivo de conseguir informações. $\mathrm{O}$ autor cita como exemplo os consultores e os organismos governamentais. $\mathrm{O}$ terceiro tipo, a rede social, é composta pelos amigos e a família.

Freitas e Heineck (2014) e Lopes (2011), por sua vez, trabalham com a existência de três tipos de rede: comercial, social e técnica. A rede técnica é representada pelo fluxo de informações técnicas trocadas entre os atores participantes da rede, como por exemplo a forma em como determinado método de trabalho é realizado dentro de uma empresa. A rede comercial é representada pela troca de informações de conteúdo comercial, como a avaliação de fornecedores comuns ou a comparação de preços de insumos. A rede social é caracterizada por ligações de natureza social, como aquelas de amizade e parentesco.

Quanto à forma de analisar as redes, Zaheer, Gözübüyük e Milanov (2010) identificam três níveis de análise na literatura: a díade, o ego ${ }^{6}$ e a rede como um todo. No nível da díade, os pesquisadores focam nas características do relacionamento entre duas organizações. A questão chave desse nível de análise é entender a natureza do relacionamento entre atores em termos de características relacionais, tais como a fortaleza dos laços e o grau de confiança e em como essas características relacionais afetam a probabilidade de renovação do relacionamento, continuação, dissolução e ou outros resultados. Pesquisas no nível de análise do ego referem-se ao tipo de efeitos que a rede tem sobre o comportamento e desempenho do ego. Mais especificamente, estes efeitos resultam das conexões do ego, das conexões entre alter ego, das características do alter ego e da posição estrutural do ego dentro de toda a rede. Assim, o locus de atenção não é a característica de cada relacionamento em si, mas antes a estrutura das relações circundante. Portanto, os principais conceitos de análise nesse nível são os seguintes: centralidade, buraco/fechamento estrutural e equivalência estrutural. No nível da rede como um todo, estudiosos predominantemente investigam as características e o comportamento do todo interorganizational, como por exemplo, sua centralização e a análise dos resultados em todo o nível da rede. Portanto, cabe destacar que a análise eleita para a presente pesquisa está baseada na rede como um todo.

As redes, por sua vez, simultaneamente, aumentam e constrangem o poder dos atores. Zaheer; Gözübüyük e Milanov (2010) citando Aldrich e Pfeffer, (1976), Mizruchi, (1989) e Pfeffer e Salancik (1978, 2003), esclarecem que o locus de poder nos relacionamentos interorganizacionais deriva da teoria de dependência dos recursos, a qual sugere que o poder dos parceiros sobre uma firma focal aumenta com o crescimento da dependência da firma dos recursos daqueles parceiros. Além de observar, a partir de uma perspectiva estrutural, o poder individual na díade, a pequena empresa pode restringir o poder de uma empresa poderosa, trazendo terceiros para a rede.

Redes também são estruturas promotoras da confiança. Observa-se que um maior encerramento (a medida que os alter ego são ligados uns aos outros) numa rede leva a uma maior confiança global. Assim, o nível de confiança está associado a baixos custos de transação, o que aumenta a eficiência das relações interorganizacionais, tais como de alianças e joint ventures (BEAMISH; LUPTON, 2009).

Dois aspectos das redes sociais afetam a confiança. Um é 'relacional' e tem a ver com a história particular desse laço que produz concepções de cada um em relação ao outro. O outro é 'estrutural', uma vez que em algumas estruturas de rede é mais fácil do que em outras desenvolver relacionamentos

6 No jargão de redes “ego" refere-se ao ator focal (a empresa ou organização) e “alter” para os atores (ou seja, empresas) com quem o ego está conectado na rede (Zaheer; Gözübüyük \& Milanov, 2010). 
de confiança e evitar prevaricação. Por exemplo, uma densa rede com muitas conexões espalha muito mais facilmente a informação sobre os aspectos positivos e negativos da reputação de seus componentes (CASTILLA et al., 2000).

De acordo com Granovetter (2005) a estrutura social, especialmente sob a forma de redes sociais, afeta os resultados econômicos por três razões principais. Em primeiro lugar, as redes sociais afetam o fluxo e a qualidade da informação. Muita informação é sutil, pouco nítida e de difícil verificação, por isso os atores não acreditam em fontes impessoais, preferindo recorrer a pessoas que eles conhecem. Em segundo lugar, as redes sociais são uma importante fonte de recompensa e punição, uma vez que ampliam seu impacto quando proveniente de outros conhecidos pessoalmente. Em terceiro lugar, há confiança de que os outros vão fazer a coisa "certa", apesar de um claro equilíbrio de incentivos ao contrário no contexto de uma rede social.

Granovetter (2005) apresenta quatro princípios fundamentais importantes, embora não devam eles receber tratamento axiomático, para entender em como as estruturas sociais e as redes sociais afetam os resultados econômicos, tais como contratação, preço, produtividade e inovação ${ }^{7}$. Os princípios são os seguintes:

a) Normas e densidade da rede - Normas são ideias compartilhadas sobre a maneira correta de se comportar. São mais claras, mais solidárias e mais fáceis de aplicar se a rede social é densa. (Se uma rede social é composta por n "nós", pessoas, empresas ou outras unidades sociais, então a densidade é a proporção da possível n (n - 1) / 2 ligações entre os nós que estão realmente presentes). Assim, uma maior densidade faz as ideias sobre o comportamento adequado mais provável de ser encontrado repetidamente, discutido e fixado. Torna também o desvio das normas mais difícil de ser escondido e, portanto, mais suscetível de serem aplicadas as punições.

b) A força dos laços fracos - informações fluem mais para os indivíduos através dos laços fracos do que através de laços fortes. Isso ocorre devido ao fato dos amigos próximos tenderem a se mover nos mesmos círculos, daí as informações que recebem se sobrepõem consideravelmente ao que já sabiam. Conhecidos, pelo contrário, conhecem pessoas que não conhecemos e, assim, recebem mais informações diferentes. Este resultado surge, em parte, porque nossos conhecidos são tipicamente menos semelhantes a nós do que os amigos próximos e, em parte, porque eles gastam menos tempo com isso. Movendo-se em círculos diferentes dos nossos, eles nos conectam com um mundo mais amplo. Eles podem, portanto, ser melhores fontes quando se precisa ir além do conhecimento do próprio grupo, como para encontrar um novo emprego e ou a obtenção de um serviço escasso. A implicação, em nível macro, deste argumento, é que se amigos íntimos conhecem um ao outro, eles formam um grupo unido.

c) A importância de buracos estruturais - trata-se de um conceito que amplia e reformula o argumento dos laços fracos, enfatizando que não é a importância ou a qualidade de qualquer laço em particular e, sim a forma em como as diferentes partes das redes são ligadas. Enfatiza a vantagem estratégica que pode ser apreciada por pessoas físicas com laços em várias redes, largamente separadas umas das outras. Na medida em que constituem a única via através da qual a informação ou outro recurso pode fluir de um sector da rede para outro, como pode ser dito como meio para explorar os buracos estruturais da rede.

\footnotetext{
Utiliza-se inovação nesse contexto como sinônimo de aquisição de conhecimentos e habilidades que possam alterar nos processos e os resultados das organizações. Para a presente pesquisa, interessa a aquisição de conhecimentos e habilidades relacionadas ao DS.
} 
d) A interpenetração de ação econômica e não econômica - muito da vida social gira em torno de um foco não econômico. Quando atividades econômicas e não econômicas são misturadas, a atividade não econômica afeta os custos e as técnicas disponíveis para a atividade econômica. Trata-se da inserção social da economia, na medida em que a ação econômica está ligada ou depende de uma ação ou instituições que são não econômicas em conteúdo, objetivos e ou processos.

Embora a atuação em rede possa, muitas vezes, implicar em constrangimentos para seus membros, a literatura é mais vasta em relação aos benefícios e vantagens que podem ser angariados pela participação nesse tipo de estrutura.

Entre os benefícios identificados é interessante ressaltar as proposições de Balestrin e Vargas (2004) que apresentam evidências teóricas e empíricas indicando que a configuração em rede permite às PMEs atingirem ainda os seguintes benefícios: participação e vendas de produtos em feiras, lobbying, melhoria nos processos empresariais, participação em palestras e cursos de formação, barganha de preço junto aos fornecedores, marketing conjunto, acesso a novos representantes, maiores garantias no fornecimento de crédito aos clientes, maior facilidade de comercialização de insumos entre as empresas e ganhos de economias de escala, de escopo e de especialização. E ainda as considerações de Bessant e Tsekouras (2001), Tomáel, Alcará e Di Chiara (2005) que reforçam a noção de que as redes aumentam o conhecimento e a capacidade de seus membros.

Por fim, cabe destacar os cinco modelos de rede apresentados por Quinn, Anderson e Finkeltein (2001), que ilustra conforme a Figura 1 os 5 (cinco) tipos de redes, como segue:

- Rede infinitamente plana - O ponto Dc representa o agente central desempenhando o papel de fornecedor e de coordenador de formações ou de conhecimento para capacitação dos nós no enfrentamento dos desafios cotidianos e para inovação, não havendo a necessidade de comunicação entre os nós. Esses nós são autônomos, pois têm Dp, E e R;

- Rede invertida - o conhecimento ou o know how circula livremente de nó para nó, ou formalmente para o centro quando definido pelo modelo de gestão. Nesse caso, o centro poderia funcionar como uma memória do conhecimento gerado na rede. A principal característica da rede invertida é que o local de controle centraliza a maior parte dos recursos (humanos, financeiros e logísticos) necessários à operação da rede.

- Rede teia de aranha - nessa rede, todos os nós são autônomos e não existe um agente central, mas para melhorar a eficiência de atendimento, os nós precisam interagir trocando informações e conhecimentos operacionais.

- Rede aglomerada - A semelhança dessa rede com a "teia de aranha" é observada apenas no que se refere às trocas de informação e de conhecimento operacional, mas o modelo de gestão que orienta o funcionamento da rede aglomerada é bastante diferente. Tal rede é formada por nós que realizam atividades contínuas e permanentes, esses nós são chamados de unidades, e por nós que executam tarefas situacionais, que recebem o nome de equipes. As equipes são formadas para resolver um problema e contam com especialistas das unidades que funcionam como centros de desenvolvimentos de competências em temas ou em disciplinas específicas.

- Rede "raio de sol" - Esse tipo de rede dissemina o conhecimento e/ou o poder decisório e/ou os recursos do centro para os nós que atendem aos usuários, podendo haver nós intermediários, que também podem gerar conhecimento ou captar recursos que serão repassados aos nós de atendimentos. 
Figura 1 - Representação esquemática dos tipos de redes

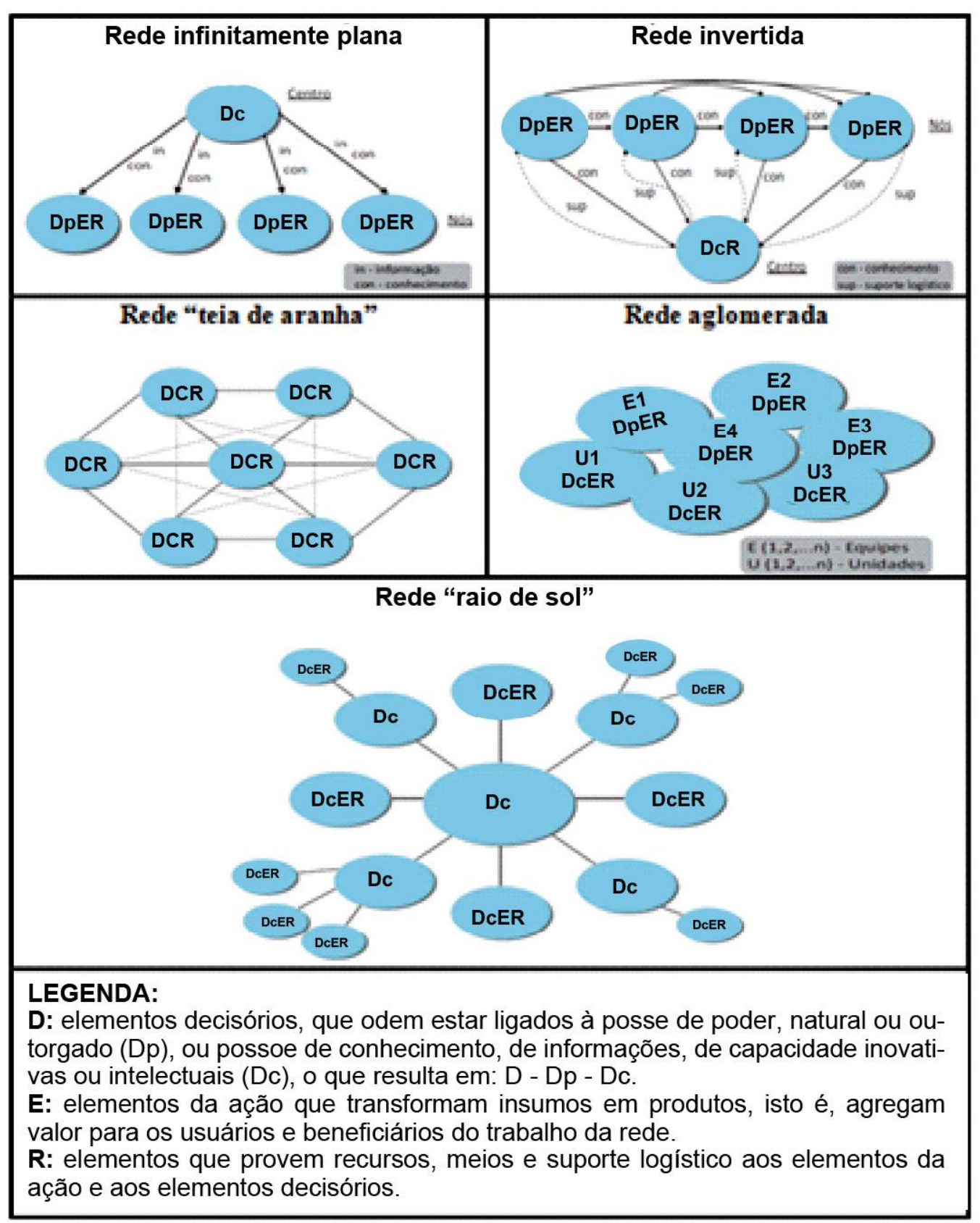

Fonte: Quinn, Anderson \& Finkelstein (2001)

\section{METODOLOGIA}

A abordagem metodológica adotada aponta para a pesquisa qualitativa. Flick (2004, p. 18) ressalta que a era das grandes narrativas e teorias chegou ao final: "as narrativas devem ser limitadas em termos locais, temporais e situacionais", o que obriga a utilização de estratégias indutivas, ao invés de partir de teorias para testá-las, embora a criação de conceitos sensibilizantes seja influenciada por um conhecimento teórico anterior.

O objeto da presente pesquisa são as redes formadas para o processo de aprendizagem de conhecimentos e práticas sobre sustentabilidade, considerando as relações entre os componentes do arranjo da piscicultura do Açude Castanhão, que segundo Souza (2010), é composto por empresas produtoras de tilápia, fornecedoras de gelo, alevinos, juvenis, ração, gelo e gaiola (ou seus insumos) e outros equipamentos; 
distribuidoras e comercializadoras; consumidoras; organizações governamentais e não governamentais, voltadas à formação e treinamento de recursos humanos, informação, pesquisa, desenvolvimento e engenharia, promoção e financiamento; cooperativas, associações e demais órgãos de representação.

Documentos mais atuais fornecidos pela Secretaria de Desenvolvimento Econômico, Turismo, Aquicultura e Pesca de Jaguaribara (SEDETA, 2013; SEDETA, 2015), apontam para o seguinte número de componentes do APL, assim distribuídos e elencados na Figura 2, a seguir:

Figura 2 - Componentes do APL da piscicultura do Castanhão

\begin{tabular}{|c|c|}
\hline Componentes do APL & Número \\
\hline Piscicultores Individuais & Desconhecido \\
\hline Associação e cooperativas que congregam piscicultores individuais & 09 \\
\hline Processadores de pescado & 02 \\
\hline Fornecedor de Ração & 07 \\
\hline Fornecedor de Alevino & 04 \\
\hline Fornecedor de Gelo & 02 \\
\hline Fornecedor de equipamentos & 03 \\
\hline Instituição de apoio & 14 \\
\hline
\end{tabular}

Fonte: Adaptado de SEDETA (2013) e SEDETA (2015)

Para atender ao objetivo da pesquisa, optou-se por narrar as histórias, centradas na coleta de experiências dos participantes, no sentido de compreender de que forma a vivência na rede contribui para a aprendizagem de conhecimentos e práticas que, eventualmente, culminem com o desenvolvimento sustentável da região. Optou-se por utilizar a análise de narrativas como abordagem de interpretação dos resultados, pois se entendeu ser esta uma perspectiva analítica que possibilitaria "olhar" as informações coletadas de forma holística, integrando os dados coletados e construídos nas várias fontes mencionadas (ZACCARELLI \& GODOY, 2014).

Uma pesquisa pode conter estes vários níveis simultaneamente. Sendo assim, elegeu-se como forma de contação da história da aprendizagem de conhecimento e práticas sustentáveis no APL da piscicultura do Castanhão, os relatos interpretativos baseados em entrevistas, observação de trabalho de campo, assim como de análise de documentos, em que também se contam histórias de outras histórias (RIESSMAN, 2008 apud ZACCARELLI; GODOY, 2014).

O material básico sobre o qual o trabalho se apoiou é representado por uma série de entrevistas com os participantes do APL da piscicultura do Açude Castanhão, que inclui empreendedores do núcleo produtivo não oneroso, empresários do núcleo produtivo oneroso ${ }^{9}$, representantes de órgãos governamentais e não governamentais e agências de crédito que trabalharam na implantação e desenvolvimento do arranjo, assim como representantes de cooperativas e associações ligadas à piscicultura. Ressalte-se que se trata de uma escolha intencional e por acessibilidade, em que se buscou, a partir de levantamentos preliminares, conhecer aqueles atores que apresentam maior relevância

$\overline{8}$ Optou-se por não elencar o mercado consumidor. 
para a consecução das atividades do APL. A identificação dessa relevância foi construída à medida em que as entrevistas se efetivaram. Para a realização das entrevistas, optou-se por 03 (três) roteiros semiestruturados como instrumento de coleta, sendo cada um deles direcionados aos segmentos: produtor, cooperativas/associações e instituições de apoio.

Cabe ressaltar que foram 32 pessoas entrevistadas e realizadas 9horas, 49minutos e 55 segundos de entrevista. Este tempo foi distribuído entre 12 (doze) entrevistas individuais e 6 (seis) aplicadas a um pequeno grupo de pessoas.

A observação direta também foi utilizada como fonte de coleta, porque possibilita ver o que não é percebido rotineiramente, além de aclarar fatos que as pessoas não informariam voluntariamente, possibilitando ir além da percepção de outros, desenvolvendo-se uma visão mais compreensiva (PATTON, 2002).

Sobre a pesquisa documental, Godoy (1995, p. 21) a define como sendo "o exame de materiais de natureza diversa, que ainda não receberam um tratamento analítico ou que podem ser reexaminados, buscando-se novas e ou interpretações complementares". Os documentos analisados foram principalmente leis, mas também relatórios de atividade fornecidos pela Associação Cearense de Aquicultura (ACEAQ), SEDETA e Departamento Nacional de Obras Contra a Seca (DNOCS).

A estrutura narrativa eleita consiste na fase de análise e discussão dos resultados propriamente dita, em que a etapa de descrição de como as redes foram se constituindo no processo de aprendizagem de conhecimentos e práticas sobre sustentabilidade é simultaneamente relacionada às categorias de análises sugeridas no referencial teórico sobre redes.

Por fim, para validação da história narrada, Silverman (2009) aponta que têm duas formas sugeridas como particularmente apropriadas: 1) comparar tipos diferentes de dados (por exemplo, quantitativos e qualitativos) e diferentes métodos (por exemplo, observação e entrevistas) para ver se eles corroboram um com o outro. Essa forma de comparação é chamada de triangulação, derivada da navegação, em que rumos diferentes dão a posição correta do objeto e 2) retornar os achados aos sujeitos que estão sendo estudados. Portanto, para a presente pesquisa, utilizou-se das duas estratégias, pois além de fazer uso de diferentes fontes de dados e métodos, a história foi apresentada a um dos entrevistados do núcleo institucional para corroboração dos dados contidos. A escolha desse entrevistado recaiu sobre o fato de participar ativamente do movimento da piscicultura, não só como agente econômico no arranjo produtivo, mas também como agente público, além de demonstrar disponibilidade, capacidade intelectual e criticidade.

\section{REDES INTERORGANIZACIONAIS: AS INTERAÇÕES POSSÍVEIS}

A construção do açude, que culminou com a mudança de localização da cidade de Jaguaribara, em 2001, causou enorme transtorno. Com essa mudança, a cidade teve sua estrutura social e econômica inteiramente alterada (LIMA, 2007).

Do ponto de vista social, as pessoas seriam realocadas seguindo planejamento idealizado pelo DNOCS, que com a ajuda do Instituto de Desenvolvimento Agrário do Estado do Ceará (IDACE), a serviço da Secretaria de Desenvolvimento Agrário (SEAGRI, atual SDA), cadastrou todas as pessoas atingidas pela barragem.

Cabe destacar que, para a construção do Castanhão e o reassentamento involuntário das pessoas do entorno (rural e urbana), constituiu-se um grupo multiparticipativo que envolvia todos os segmentos da cidade, inclusive o Movimento do Atingidos por Barragens (MAB), a igreja, os produtores rurais, 
os pescadores, os comerciantes, os moradores da cidade e do campo, as lavadeiras, DNOCS, Governo do Estado e Prefeitura Municipal de Jaguaribara (LIMA, 2007).

Aquelas que não tinham terras, antes da conclusão da obra do Castanhão, seriam encaminhadas para 17 reassentamentos margeando o açude. Já os fazendeiros, proprietários de terras, seriam indenizados e as pessoas que moravam na cidade receberiam uma casa, seguindo os parâmetros anteriores da antiga cidade. As pessoas dos reassentamentos seriam realocadas segundo a sua atividade econômica que seriam estimuladas na região, como: bovinocultura, caprinocultura, apicultura, avicultura e fruticultura e outras inovadoras, como a piscicultura.

A piscicultura logo começou a chamar a atenção devido a imensidão do espelho d'água, mas o único conhecimento que as pessoas da região possuíam sobre atividades econômicas aquáticas era a pesca artesanal em águas rasas de rios, riachos e lagoas, só que agora teriam que praticá-la em águas represadas com até 60 metros de profundidade, em um lago artificial de $325 \mathrm{~km} 2$ (na cota 100 metros), que parecia mais um pequeno mar de água doce (MATIAS, 2010).

Para iniciarem suas atividades, mesmo com muitas dificuldades, surgiram as primeiras ações em que se identifica a participação de diversos atores públicos na tentativa de possibilitar uma saída econômica para a grande maioria da população reassentada, no sentido de permitir ao pequeno empreendedor se estabelecer na atividade da piscicultura.

Portanto, a forma inicial pensada para a realização das ações, seria em rede de cooperação, afinal o objetivo era grandioso: pensar atividade econômica para pessoas que estavam passando por um processo de reassentamento involuntário. Entretanto, estas sementes da cooperação já tinham sido lançadas, haja vista os resultados satisfatórios de participação obtidos pelo Grupo Multiparticipativo (LIMA, 2007).

Ocorreu que quando das primeiras iniciativas para o desenvolvimento da piscicultura, ainda em funcionamento do Grupo Multiparticipativo, um conjunto de órgãos (DNOCS, SEAGRI/DAS, IDACE, Prefeitura Municipal de Jaguaribara (PMJ) e Serviço Brasileiro de Apoio às Micro e Pequenas Empresas (SEBRAE)) passaram a cooperar entre si, para ajudar a população a resolver seus problemas econômicos, cuja forma de atuação gerou uma rede com características de infinitamente plana (QUINN; ANDERSON \& FINKELSTEIN, 2001), haja vista que os agentes públicos passaram a desempenhar o papel de fornecedor e de coordenador de recursos informacionais, financeiros e materiais para empoderamento dos nós (membros da sociedade civil em processo de formação dos assentamentos). A Figura 3 retrata esta configuração:

Figura 3 - Representação da rede que deu base à rede da piscicultura

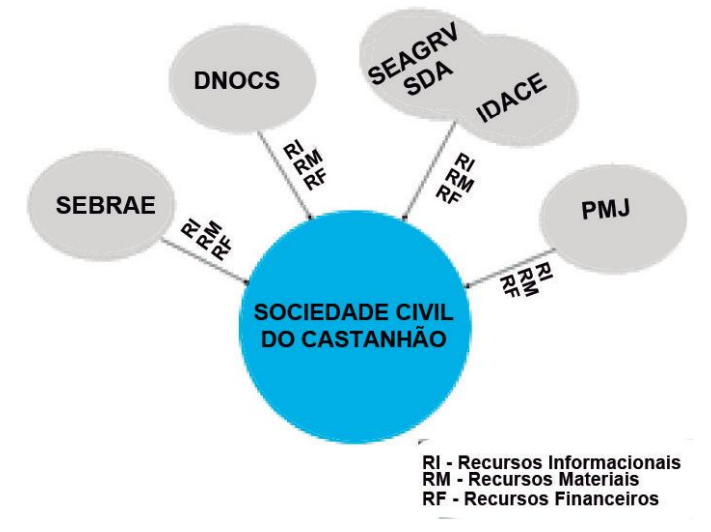

Fonte: Elaborado pelos autores (2017). 
Uma vez lançadas as sementes para o desenvolvimento das atividades produtivas, o primeiro grupo que surgiu especificamente para a operacionalização da piscicultura foi o Grupo Pioneiro, que se constituiu dos primeiros sete empreendedores interessados em iniciar as atividades da piscicultura. Tratava-se de uma rede bastante densa, haja vista que dentro dela era possível serem encontradas 21 ligações das 21 interações possíveis (7x (6) / 2) entre os nós. Esta elevada densidade é demonstrada, principalmente quando considerada a forma como as tarefas de produção e comercialização eram realizadas, com rodízio e contribuição de todos em todas as funções. Como nessa estrutura de interação não existia uma hierarquia rígida entre o líder e os outros membros, a comunicação ocorria em todos os sentidos, o que caracteriza a rede como do tipo teia de aranha.

Embora os membros não fossem totalmente autônomos, pois compartilhavam as responsabilidades para pagamento do financiamento que foi feito com aval solidário entre os participantes do grupo, critério este que também levava a maior proximidade entre os membros e uma definição clara do comportamento apropriado para cada um dos membros do grupo. Como lembra Granovetter (2005), em uma rede densa é mais fácil apresentar as ideias sobre o comportamento adequado e mais provável de ser encontrado, discutido e fixado. Afinal, estas normas de comportamento são ideias compartilhadas sobre a maneira correta de se comportar, então são mais prováveis que sejam mais claras, mais solidárias e mais fáceis de aplicar.

Considerando ainda a proximidade territorial em que os membros se encontravam, muitas vezes com laços de amizade e parentesco, é correto ainda afirmar que foi possível observar a existência de laços fortes entre os componentes do grupo. Por outro lado, quando considerada a relação com as entidades apoiadoras, também se observava a existência de laços fracos (GRANOVETTER, 1983).

A Figura 4 mostra a configuração desta rede, ressaltando o formato de figura teia de aranha (QUINN; ANDERSON; FINKELSTEIN, 2001). Em acréscimo, poderia também ser caracterizada como rede infinitamente plana se representada com suas relações com as entidades apoiadoras.

Figura 4 - Representação da rede do Grupo Pioneiro

\section{GRUPO PIONEIRO}

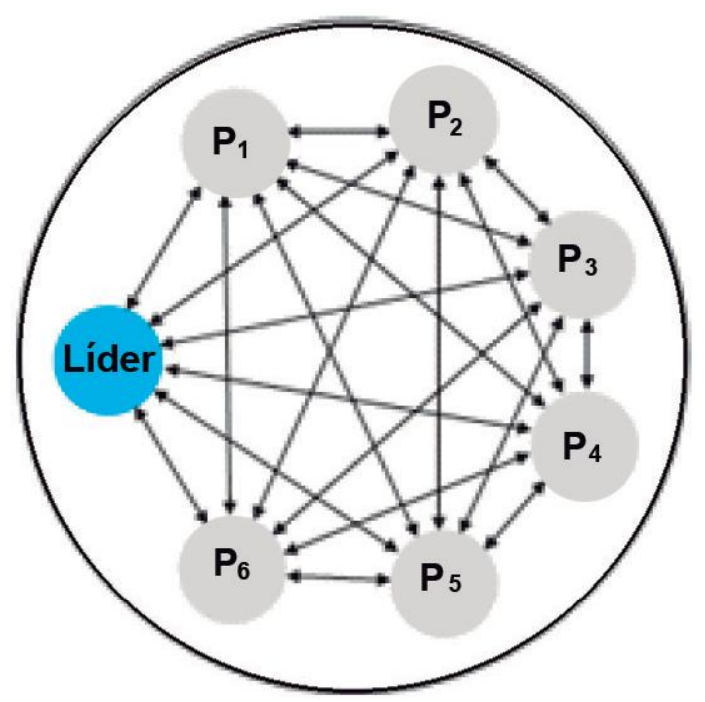

Fonte: Elaborado pelos autores (2017). 
A partir do sucesso alcançado pelo Grupo Pioneiro, foi constituída a Associação dos Pescadores da Barragem Castanhão (ASPBC) com a inserção de mais seis grupos, além do Grupo Pioneiro. Para coordenação das atividades, além das regras de conduta e escala de trabalho já conhecidas do Grupo Pioneiro, foi estabelecida uma diretoria formada pelos líderes de cada um dos sete grupos que formavam a associação. Neste caso, observa-se a formação de rede do tipo invertida (QUINN; ANDERSON; FINKELSTEIN, 2001), pois esse centro, composto pela diretoria, funcionava como uma memória do conhecimento gerado na rede, constituindo em importante meio de troca de conhecimento e práticas entre os grupos. Com isso, observou-se novamente uma configuração bastante densa entre os sete grupos produtivos, pelo estabelecimento desta diretoria. Internamente aos grupos, por sua vez, mantinham a alta densidade entre os membros, o que continuava a manutenção das características da rede do tipo teia de aranha. A Figura 5 representa esquematicamente esta discussão.

Figura 5 - Representação da rede da ASPBC

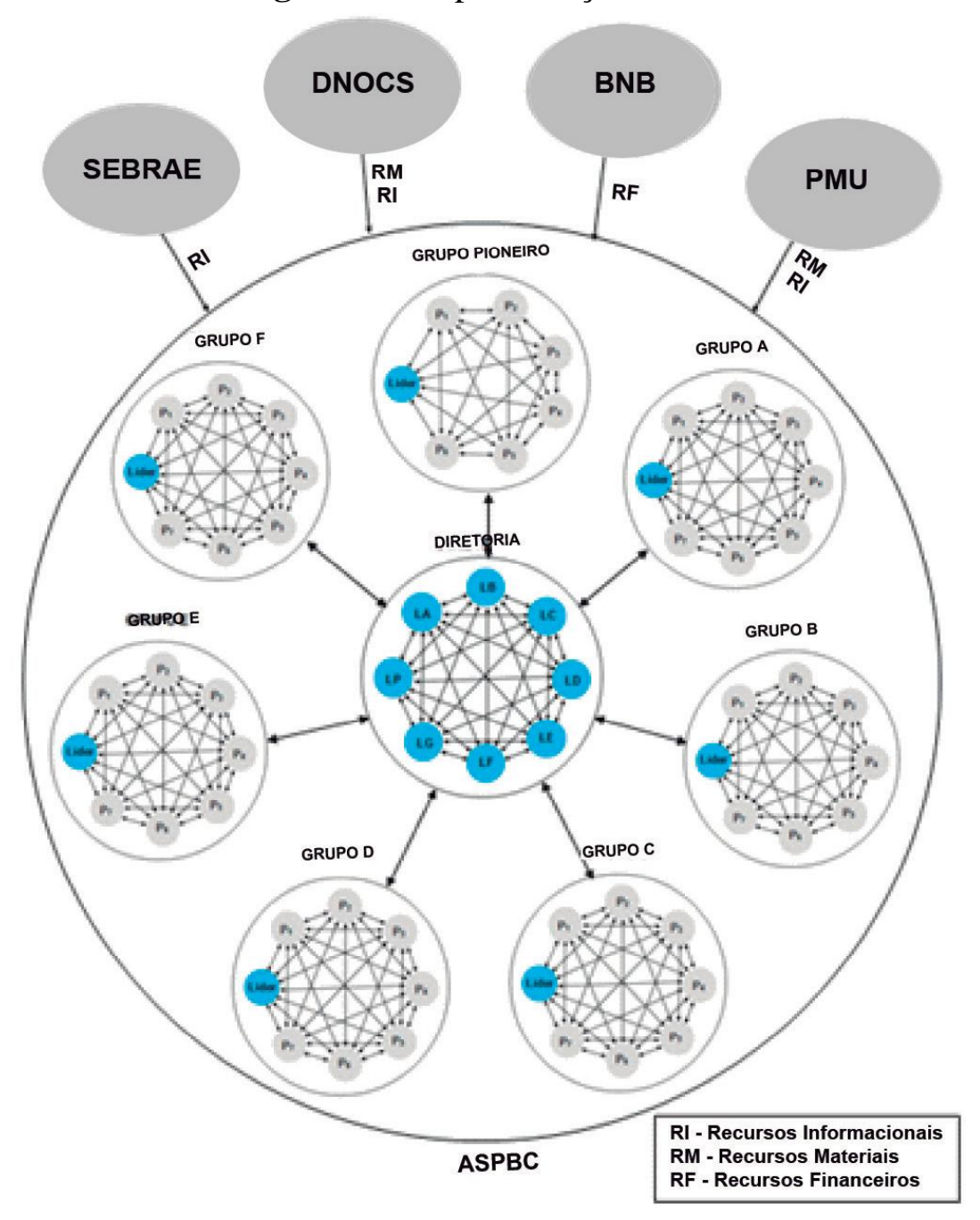

Fonte: Elaborado pelos autores (2017).

Pode-se, ainda, afirmar que a configuração em rede que se constituiu para a operacionalização da ASPBC, apresentava características mistas de rede em teia de aranha, invertida e infinitamente plana, sendo a permanência deste último tipo devido a manutenção de agentes fornecedores de recursos (QUINN; ANDERSON; FINKELSTEIN, 2001) 
Apesar de se constituir também em uma rede bastante densa e composta tanto por laços fortes quanto fracos, a ASPBC acabou se dissolvendo devido a problemas que ocorreram dentro dos grupos como desvio de conduta de alguns líderes e ou membros dos grupos. Conforme depoimentos, além de serem os primeiros, não possuíam experiência tanto com a produção quanto com a cooperação.

Por outro lado, vários modelos jurídicos de organização de redes de cooperação puderam ser testados no Castanhão. Enquanto as outras entidades tinham optado pela criação de associações, em que os trâmites comerciais eram em nome dos sócios, no Projeto Curupati Peixe, a orientação dos técnicos era de que a forma jurídica que mais facilitaria o funcionamento seria a cooperativa. Enquanto nas associações o compartilhamento das atividades era parcial, na Cooperativa dos Piscicultores do Curupati Peixe (CPCP) tudo era compartilhado. Não eram produtores autônomos, existia uma escala de atividades que era elaborada e acompanhada pela diretoria. A tipologia de rede que se aplica no caso é a invertida, pois o conhecimento circula livremente de nó para nó e, formalmente, para o centro, composto pela diretoria, como definido pelo modelo de gestão. A comunicação era bastante fluida, bem como a diretoria precisava ser renovada periodicamente. De fato, o verdadeiro "patrão" de todos, eram as regras rígidas, estabelecidas nas assembleias com a participação de todos os cooperados, que impõem punições severas para os desvios de conduta, como o afastamento do produtor de suas atividades com redução nos seus ganhos mensais, assim como a expulsão sumária da cooperativa, mas mediante o recebimento da cota parte. Embora, caiba destacar que todo o patrimônio inicial da cooperativa foi doado pelos governos estaduais e federais, portanto entre os cooperados não existia o vínculo do aval solidário.

Observou-se também que desde o momento da sua constituição até a realização desta pesquisa, existe uma forte governança externa, anteriormente exercida pela SEAGRI/SDA e atualmente pela Secretaria de Pesca e Aquicultura (SPA), além de contar com o apoio de várias entidades que contribuíram para sua constituição e continuidade, por isso que a configuração em rede para a CPCP apresenta também um misto de rede infinitamente plana e invertida (QUINN; ANDERSON; FINKELSTEIN, 2001). A Figura 6 abaixo ilustra esta forma de organização:

Figura 6 - Representação em rede da CPCP

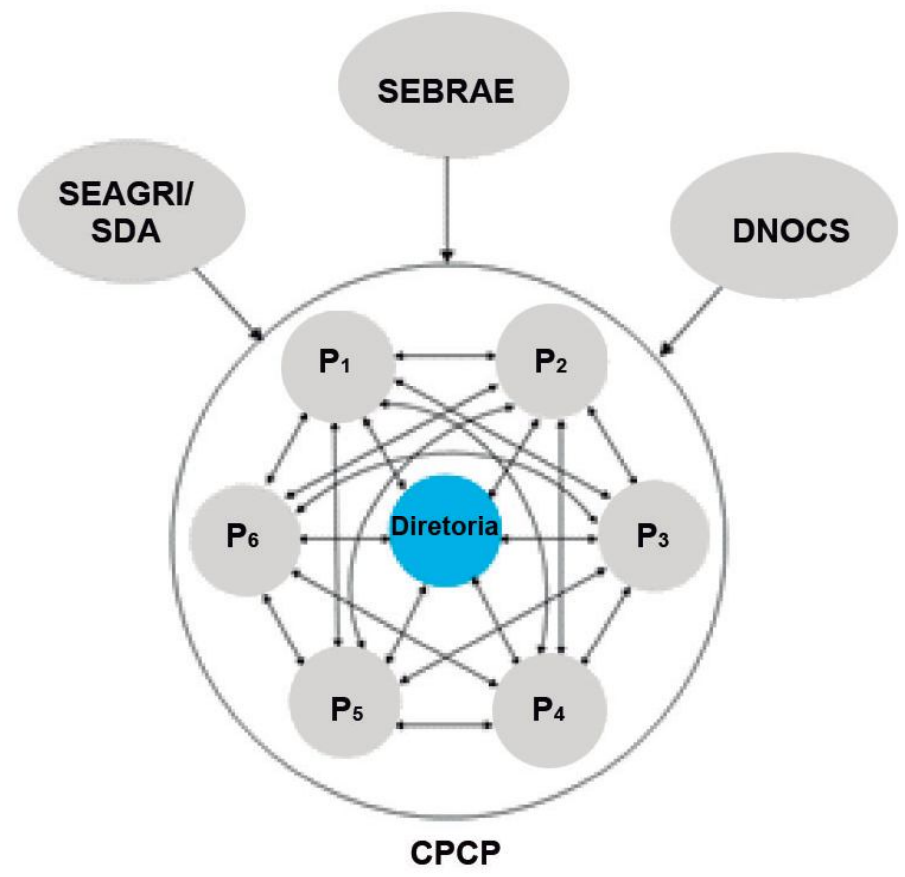

Fonte: Elaborado pelos autores (2017). 
No ano de 2005 foi constituída a Associação dos Criadores de Tilápia do Castanhão (ACRITICA), que seguiu moldes da ASPBC. Surgiu para facilitar o gerenciamento do pagamento dos financiamentos, apresentar facilidade no manejo das fazendas aquícolas e, ainda, obter vantagens nas compras conjuntas. Diferentemente da ASPBC, a ACRITICA não se desfez, mas com o pagamento dos financiamentos, a organização evoluiu para um organograma em rede de pequenos grupos, só que desta vez, não mais orientado pelo grupo constituído para o aval solidário, mas pela convivência em associação, em que cada um já tinha percebido com quem era mais fácil trabalhar e confiar, pois conforme Castilla et al. (2000), uma densa rede com muitas conexões espalha muito mais facilmente a informação sobre os aspectos positivos e negativos da reputação de seus componentes.

A ACRITICA, contudo, continuou sendo a responsável pela compra conjunta de ração e por parte da comercialização do pescado, utilizando-se da parceria entre os produtores, além de ainda manter a função de informar aos produtores sobre a quantidade de ração que deve ser empregada por dia conforme o tamanho do peixe, bem como repassar conhecimento e organizar o Festpeixe ${ }^{10}$ juntamente com a PMJ.

A ACRITICA também tem uma configuração em rede do tipo mista em que se evidenciam a rede infinitamente plana e invertida (QUINN; ANDERSON; FINKELSTEIN, 2001), como demonstra a Figura 7 a seguir:

Figura 7 - Representação da rede da ACRITICA

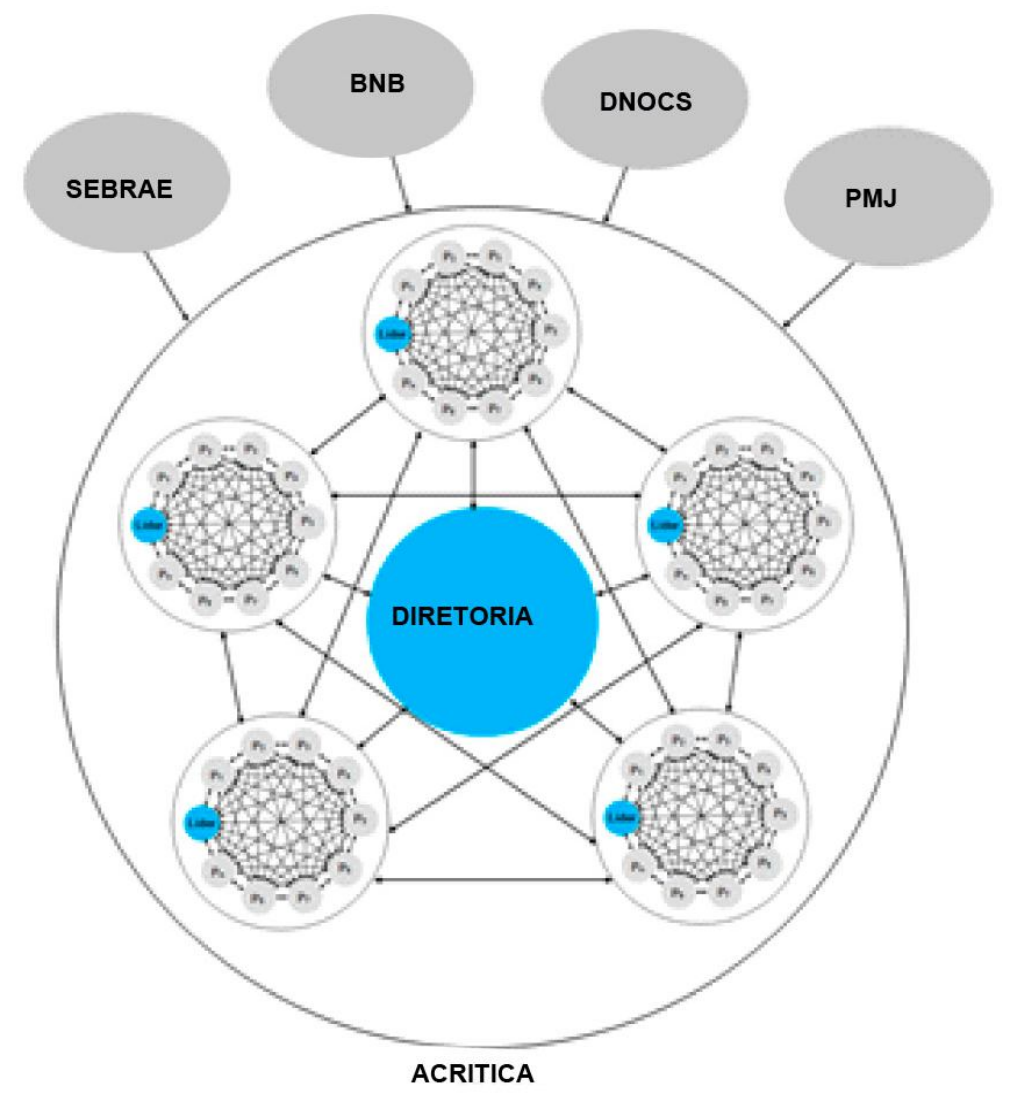

Fonte: Elaborado pelos autores (2017).

$\overline{10}$ Festival que ocorre geral mente no mês de julho. 
Em 2005 também foi constituída a Associação de Produtores e Processadores de Peixes de Jaguaribara e Lages (APLAGES). Mesmo possuindo uma rede densa entre os membros de cada grupo e em forma de teia de aranha, sua configuração em rede é um pouco diferente das outras associações, haja vista que existe hierarquia na distribuição dos recursos (insumos), formando uma rede que Quinn, Anderson e Finklestein (2001) denominam como raio de sol. O grupo da produção repassa os peixes para os grupos da taxidermia e beneficiamento, enquanto que o grupo do beneficiamento repassa os insumos necessários para o artesanato e o sabão, fazendo daquele um nó intermediário, como ilustra a Figura 8 a seguir:

Figura 8 - Representação em rede da APLGES

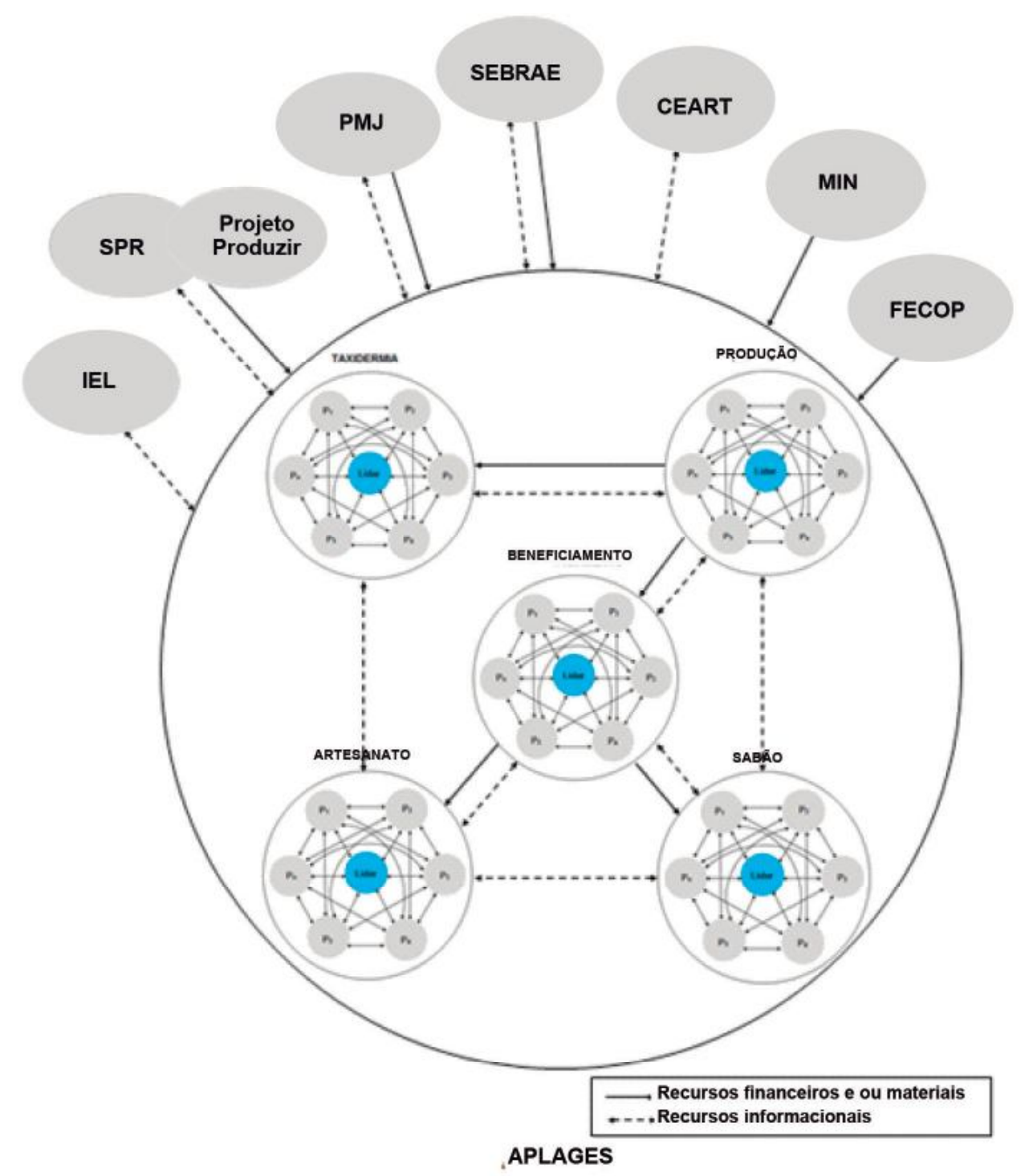

Fonte: Elaborado pelos autores (2017).

Devido a proximidade espacial de todos os pequenos produtores, observa-se a interpenetração de ações econômicas e não econômicas (GRANOVETTER, 2005), que influenciavam nas regras e comportamentos aceitos pelos grupos. Em alguns casos, levando à dissolução dos grupos, em outros tornando as interações mais confiáveis. Cabe destacar que a Associação também recebeu aporte financeiro a fundo perdido para que suas atividades fossem instaladas, mas diferentemente da CPCP não logrou tanto êxito no funcionamento de suas atividades, resultando em ações de diversificação da 
atividade da piscicultura ainda muito incipientes. Até o desenvolvimento desta pesquisa a unidade de beneficiamento ainda não tinha obtido selos de inspeção sanitária.

AAssociação Cearense de Aquicultores (ACEAQ) foi outra rede formada para o compartilhamento de informações, que viria congregar não só os produtores do Castanhão, mas de todo o Estado. Além do papel de representação do setor, também funciona como disseminador de boas práticas de produção e catalizador de informações e recursos. Também se constitui em elemento fundamental na Câmara Setorial da Tilápia (CSTilápia), que é formada por representantes dos setores produtivo, governamental, tecnológico e científico, como demonstra a Figura 9 a seguir:

\section{Figura 9 - Representação da rede da ACEAQ e da CSTilápia}

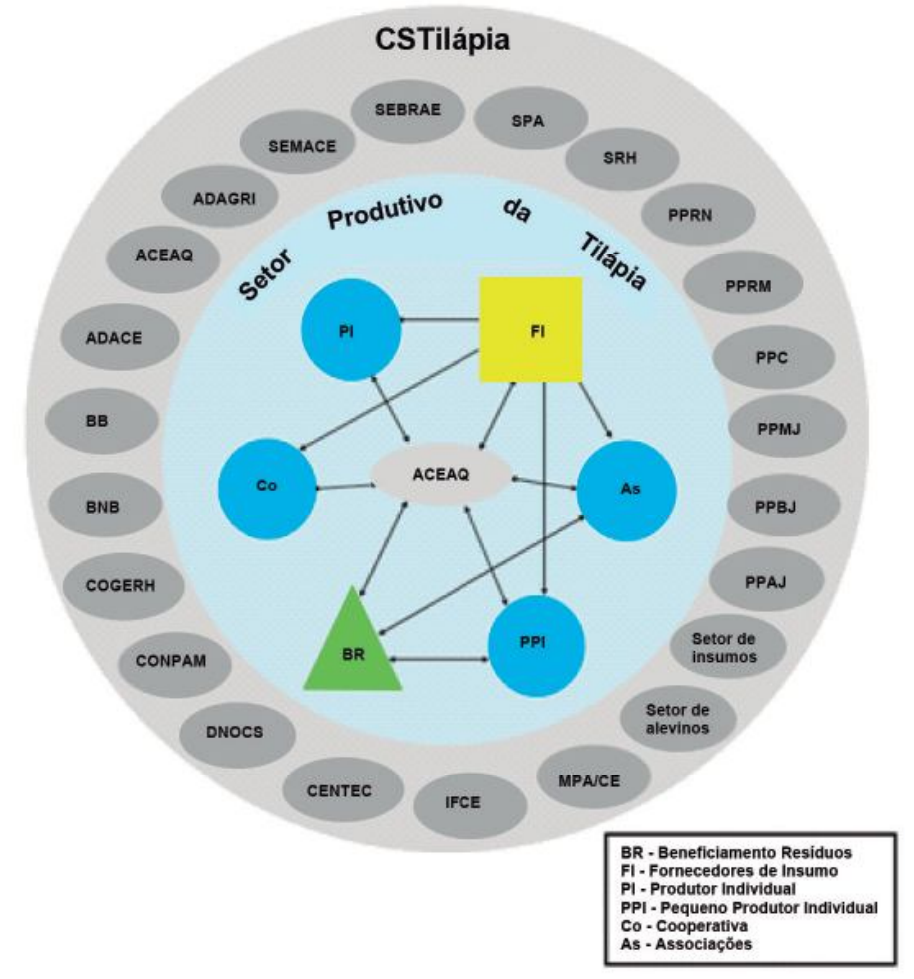

Fonte: Elaborado pelos autores (2017).

A opção por usar um círculo para representar os integrantes da CSTilápia foi para demonstrar que, assim como ocorre com a ACEAQ, os nós são completamente autônomos e as informações e conhecimento são repassados de maneira fluida e em todas as direções, perpassando o setor produtivo da piscicultura. Esta é uma rede pouco densa, que participa de reuniões pontuais e esporádicas, em que não se apresenta interpenetração entre ações econômicas e não econômicas.

Por fim, para demonstrar graficamente todos os elementos que contribuem para a disseminação de conhecimento e práticas sobre sustentabilidade, há ainda que se considerar o grupo de órgãos que trabalham na fiscalização da boa aplicação das normas federais e estaduais para manter o ambiente sustentável. Estes parecem ser os nós que carecem de mais atuação e comunicação com os participantes do APL da piscicultura do Castanhão, dado que o papel da regulamentação e fiscalização também é considerado fundamental para a aprendizagem de conhecimentos e práticas que respeitam o ambiente e as pessoas.

Elaborou-se a seguinte Figura 10 para representar todas as redes que compõem o APL da piscicultura do Castanhão e que tem contribuído para a aquisição de conhecimento e práticas que influenciam no DS da região. 
Figura 10 - Representação da rede de aprendizagem para a sustentabilidade

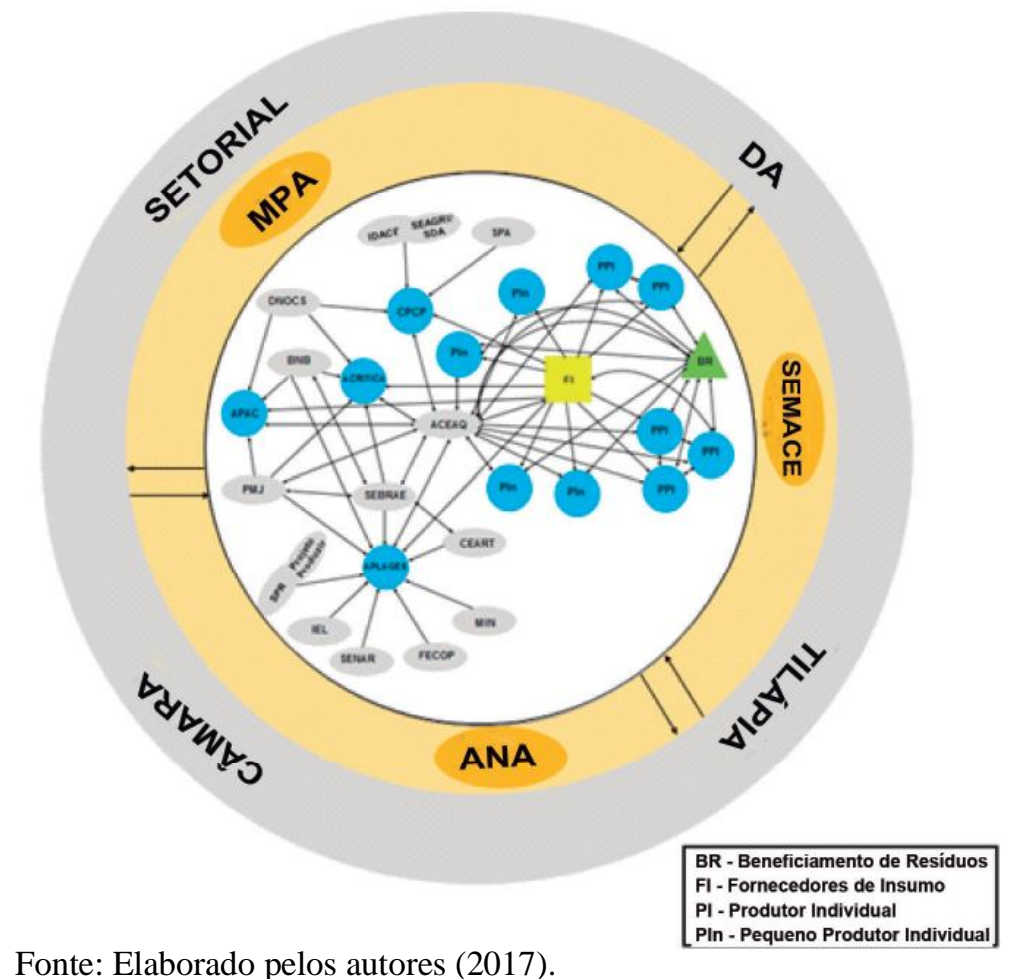

Fonte: Elaborado pelos autores (2017).

Os laços que ocorrem entre o segmento dos produtores (que incluem fornecedores de insumos e beneficiadores de resíduos da piscicultura) são fortes, mas com a chegada dos produtores individuais de grande porte, alguns laços no setor produtivo passaram a ser fracos, que por sua vez se constituíram em oportunidade de disseminação de conhecimentos completamente novos.

Optou-se, no gráfico anterior, por representar o setor produtivo de forma pouco detalhada (foram representados apenas um pequeno número de produtores, fornecedores e beneficiadores), para ficar o destaque de alguns elementos centrais na disseminação de conhecimentos e práticas, como os beneficiadores de resíduos (APLAGES, CPCP, Produtor individual e Piscis) e pelas aproximadamente 14 fábricas de ração que comercializam no Castanhão. Outro elemento central que aparece é a ACEAQ. Quanto a essa ainda cabe destacar sua posição estratégica que pode ser apreciada por pessoas físicas com laços em várias redes que são largamente separadas umas das outras. Na medida em que constituem a única via através da qual a informação ou outro recurso pode fluir de um setor da rede para outro, pode ser dito que estão sendo explorados os buracos estruturais da rede.

Por fim, as análises das entrevistas, documentos e observações revelaram que quanto aos tipos de relações, foram identificadas redes de negócios, institucionais, pessoais e informacionais, conforme tipologia de Julien (2000a apud BORGES JÚNIOR, 2004)). Foram também identificadas, conforme Szarka (1990 apud BORGES JÚNIOR, 2004), redes: de trocas, de comunicação e social e, ainda, conforme Freitas e Heineck (2014) e Lopes (2011) também foram observadas redes comercial, social e técnica.

Portanto, mesmo sendo redundante nesse trabalho, ainda é importante afirmar que as redes aumentam o conhecimento e a capacidade de seus membros (BESSANT \& TSEKOURAS, 2001; TOMÁEL; ALCARÁ \& DI CHIARA, 2005), o que foi demonstrado na descrição das redes observadas no Castanhão e que tem contribuído não só para o desenvolvimento do APL ${ }^{11}$, bem como na disseminação de conhecimentos e práticas sobre sustentabilidade. 


\section{CONSIDERAÇÕES FINAIS}

O objetivo deste trabalho foi caracterizar a estrutura das redes, identificando os atores relevantes no processo de aprendizagem de conhecimentos e práticas sobre sustentabilidade a partir das relações que ocorreram no ambiente configurado como rede inteorganizacional existente no APL da piscicultura do açude Castanhão.

Neste sentido foram descritas as redes que surgiram ao longo do processo de desenvolvimento da atividade da piscicultura do Castanhão, desde as primeiras ações conjuntas com a definição da atividade produtiva, até os dias atuais, em que se observa uma rede muito mais ampla, com participação de entidades de toda sorte, como: associações, cooperativa, pessoas físicas, pessoas jurídicas, órgãos governamentais e não governamentais. Para isso, a pesquisa apresentou e analisou uma série de gráficos de redes, no intuito de descrever a evolução do APL da piscicultura e a maneira como os conhecimentos e práticas podem ser transmitidas através das interações desta rede.

As análises indicaram que a prática de solucionar problemas utilizando a estrutura de rede é anterior às ações do APL da piscicultura, haja vista que para mobilizar esforços para possibilitar novas alternativas econômicas para a população que tinha sido reassentada com a criação da barragem do Castanhão, o governo do estado se valeu da criação de um grupo multiparticipativo que contava com a presença não só de representantes dos órgãos de governo (federal, estadual e municipal), mas também da sociedade civil. Esta análise também serviu para demonstrar que o APL da piscicultura surgiu de forma tímida, com a presença de apenas sete piscicultores, passando para um tipo de rede mais robusta com a atração de novos empreendedores "forasteiros", bem como com a inserção de novas empresas (a jusante e a montante da atividade produtiva principal)e de entidades capazes de coordenar as ações do APL, como a ACEAQ e a CSTiláia.

\section{REFERÊNCIAS}

AMARAL FILHO, J. do. Arranjo Produtivo Local: Moda ou Modo? O Povo, Fortaleza, 10 dez. 2005. Disponível em: <http://www.ric.ufc.br/biblioteca/jair_l.pdf> . Acesso em: 03 set. 2014.

BALESTRIN, A.; VARGAS, L. M. A dimensão estratégica das redes horizontais de PMEs: teorizações e evidências. Revista de Administração Contemporânea, v. 8, p. 203-227, 2004.

BEAMISH, P. W.; LUPTON, N. C. Managing joint ventures. The Academy of Management Perspectives, v. 23, n. 2, p. 75-94, 2009.

BESSANT, J.; TSEKOURAS, G. Developing learning networks. A.I. and Society, London, v. 15, n. $1 / 2$, p. 82-98, mar. 2001.

BORGES Jr, C. V. Características e contribuições das redes para o desenvolvimento das pequenas e médias empresas. In: ENCONTRO NACIONAL DE PÓS-GRADUAÇÃO EM ADMINISTRAÇÃO - ENANPAD, 28., 2004, Curitiba. Anais.... Curitiba: ANPAD, 2004. Disponível em: < http://www. anpad.org.br/admin/pdf/enanpad2004-ece-2842.pdf>. Acesso em: 24 agos. 2014.

\footnotetext{
${ }^{11} \mathrm{Na}$ discussão sobre 0 tipo de rede em que transitam as práticas e os conhecimentos sobre sustentabilidade, é importante ressaltar que esta rede se constitui especificamente de uma APL. Portanto, também é apropriado analisar as características desse tipo específico de rede - APL. Entretanto, em função dos limites de tamanho por um artigo desta natureza, optou-se por não se fazer isso neste momento.
} 
CASTELLS, M. (1999). A sociedade em rede. 2. ed. São Paulo: Paz e Terra.

CASTILLA, E. J. et al. Social networks in Silicon Valley. In: Lee, C. M.; Miller, W. F.; Hancock, M. G.; Rowen, H. S. (Eds.). The Silicon Valley Edge. Standford: Standford University Press, 2000.

CONTRACTOR, N. S.; WASSERMAN, S.; FAUST, K. Testing multitheoretical, multilevel hypotheses about organizational networks: An analytic framework and empirical example.

Academy of Management Review, v. 31, n. 3, p. 681-703, 2006.

FLICK, U. Uma Introdução à Pesquisa Qualitativa. Porto Alegre: Bookman, 2004.

FREITAS, A. A. F. DE; HEINECK, L. F. M. Acumulação de capacidades tecnológicas: evidências em empresas de construção civil constituintes de uma rede de aprendizagem, Ambiente

Construído, Porto Alegre, v. 14, n. 2, p. 7-21, abr./jun, 2014.

GODOY, A. S. Pesquisa qualitativa: tipos fundamentais, Revista de Administração de Empresas, São Paulo, v. 35, n. 3, p. 20-29, mai./jun, 1995.

GRANOVETTER, M. The impact of social structure on economic outcomes. Journal of Economic Perspectives, v.19, n.1, p.33-50, 2005.

GRANOVETTER, M. The strength of weak ties: a network theory revisited. Sociological Theory, v.1, p. 201-233, 1983.

KLEIN, L. L. et al. Análise da Relação de Dependência Empresa - rede na evolução de redes interorganizacionais. In: ENCONTRO DA ASSOCIAÇÃO NACIONAL DE PÓS-GRADUAÇÃO EM ADMINISTRAÇÃO, 38, 2014, Rio de Janeiro. Anais... Rio de Janeiro: ANPAD, 2014. Disponível em: <http://www.anpad.org.br/admin/pdf/2014_EnANPAD_EOR506.pdf>. Acesso em: 10 out. 2014.

LATOUR, B. On recalling ANT. In: LAW, J.; HASSARD, J. Actor network theory and after. Oxford: Blackwell, 1999.

Law, J. Notes on the theory of the actor network: ordering, strategy and heterogeneity. Centre for Science Studies, Lancaster: Lancaster University, 1992. Disponível em: <http://www.comp. lancs.ac.uk/sociology/papers/Law-Notes-onANT.pdf>. Acesso em: 27 jul. 2015.

LIMA, F. P. F. Castanhão: do sonho à realidade. Fortaleza: Expressão, 2007.

LOPES, V. F. Redes de aprendizagem como meio para acumulação de capacidade tecnológica em PMEs do setor da construção civil: um estudo exploratório das ligações entre os atores na perspectiva da análise das redes sociais. 2011. Dissertação (Mestrado em Administração) Universidade Estadual do Ceará, Fortaleza.

MARTES, A. C. B. et al. Fórum - redes sociais e interorganizacionais. Revista de Administração de Empresas, v. 46, n. 3, p. 10-15, 2006.

MATIAS, J. F. N. Casos de sucesso da aquicultura no Brasil. Brasília: Publicações FAO, 2010.

PATTON, M. Q. Qualitative research and evaluation methods. 3th. ed. Thousand Oaks: Sage, 2002. 
POWELL, W. W. Neither market nor hierarchy: networks in organization. Research in Organizational Behavior, v. 12, p. 295-336, 1990.

QUINN, J. B.; ANDERSON, P.; FINKELSTEIN, S.. Novas formas de organização. In: Mintzberg, H.; Quinn, J. O processo de estratégia. 3. ed. Porto Alegre: Bookman, p. 157-167, 2001.

ROMEIRO, A. R. Economia ou economia política da sustentabilidade? Texto Para Discussão. Unicamp, Campinas, n. 102, 2001. Disponível em <http://www.eco.unicamp.br/index.php/textos>. Acessado em: 17 abr. 2013.

SECRETARIA DE DESENVOLVIMENTO ECONÔMICO, TURISMO, AQUICULTURA E PESCA (SEDETA).Levantamento de dados setor aquícola - Açude Castanhão. Jaguaribara: SEDETA, 2015.

SECRETARIA DE DESENVOLVIMENTO ECONÔMICO, TURISMO, AQUICULTURA E PESCA (SEDETA). (2013). Potencialidades aquícolas do Açude Castanhão. Jaguaribara: SEDETA.

SILVERMAN, D. Interpretação de dados qualitativos: métodos para análise de entrevistas, textos e interações. Porto Alegre: Artmed/Bookman, 2009.

Souza, M. A. de. A piscicultura em tanques-rede como vetor do desenvolvimento local sustentável? o caso do Açude Castanhão - CE. Brasília, 2010.178 p. Dissertação (Mestrado) Centro de Desenvolvimento Sustentável. Universidade de Brasília, Brasília.

TAVARES, W.; MAIA, M. H. B; SILVA, F. T. Benefícios competitivos advindos do desenvolvimento de uma Aglomeração Produtiva: o caso do setor têxtil na microrregião de Campo Belo (MG). In: ENCONTRO DA ASSOCIAÇÃO NACIONAL DE PÓS-GRADUAÇÃO EM ADMINISTRAÇÃO - ENANPAD, 34., 2010, Rio de Janeiro. Anais... Rio de Janeiro: ANPAD, 2010. Disponível em: <http://www.anpad.org.br/diversos/trabalhos/EnANPAD/enanpad_2010/ ESO/2010_ESO1369.pdf>. Acesso em: 27 agos. 2014.

THORELLI, H. B. Networks: between markets and hierarchies. Strategic Management Journal, v. 7, n. 1, p. 37-51, 1986.

TOMAÉL, M. I.; ALCARÁ, A. R.; DI CHIARA, I. G. Das redes sociais à inovação. Ciência da Informação, Brasília, v. 34, n. 2, p. 93-104, 2005.

WILLIAMS, T. Interorganizational Networks: Strategic Cooperation in Different Network Types. Academy of Management Proceedings, n. 1, p. A1 - A15, 1998.

ZACCARELLI, L. M.; GODOY, A. S. "Deixa eu te contar uma coisa...”: possibilidades do uso de narrativas e sua análise nas pesquisas em organizações. Revista Gestão Organizacional, v. 6, n. 3, 2014.

ZAHEER, A.; GÖZÜBÜYÜK, R.; MILANOV, H. It's the Connections: the network perspective in interorganizational research. Academy of Management Perspectives, v. 24, n. 1, p. 62-77, 2010. 